\title{
“Obras tão dignas de memória": os periódicos do Grêmio Literário Português do Rio de Janeiro
}

\author{
"Works so worthy of memory": the periodicals of the Portuguese Literary Guild of \\ Rio de Janeiro \\ Eduardo da CRUZ* \\ Universidade do Estado do Rio de Janeiro (UERJ)
}

\begin{abstract}
RESUMO: O antigo Grêmio Literário Português do Rio de Janeiro, fundado em 1855 por um grupo de jovens portugueses trabalhadores do comércio, além de contribuir para a formação dos imigrantes lusos que trabalhavam como caixeiros, distinguiu-se de outras associações da colônia por ter como um de seus objetivos a publicação de periódicos que difundissem as obras de seus sócios. Pretendemos apresentar um breve histórico dessa agremiação, suas estratégias de crescimento e as dificuldades que enfrentaram, seus principais membros e os órgãos de imprensa que criaram. A partir da leitura da revista A Saudade ( $1^{\mathrm{a}}$ série, de agosto de 1856 a fevereiro de 1857; $2^{\mathrm{a}}$ série, de abril de 1861 a outubro de 1862) e do anuário Álbum do Grêmio Literário Português (1858), documentos do cotidiano valorizados pela História Cultural, buscaremos descortinar alguns tópicos de interesse desses literatos portugueses residentes na capital do Brasil, como as saudades da pátria, a ambientação na nova terra, as leituras que faziam e, sobretudo, a imagem do imigrante português que difundiam em suas folhas.
\end{abstract}

PALAVRAS-CHAVE: Imprensa periódica oitocentista. Imigração. Relações luso-brasileiras. Periódicos de imigrantes

\begin{abstract}
The former Portuguese Literary Guild of Rio de Janeiro, founded in 1855 by a group of young Portuguese trade workers, besides contributing to the formation of Portuguese immigrants who worked as clerks, distinguished itself from other associations of the colony for having as one of its objectives the publication of periodicals that spread the works of its members. We intend to present a brief history of this association, its growth strategies and the difficulties that it faced, its main members and the press organs that this association created. From the reading of the magazine A Saudade (First series, from August of 1856 to February of

\footnotetext{
* Doutor em Estudos de Literatura pela UFF (2013), professor de Literatura Portuguesa no Departamento de Língua Portuguesa, Literatura Portuguesa e Filologia do Instituto de Letras da UERJ, Rio de Janeiro/RJ, pesquisador do Polo de Pesquisas Luso-Brasileiras do Real Gabinete Português de Leitura, investigador colaborador do Centro de Estudos Clássicos da Faculdade de Letras da Universidade de Lisboa.eduardodacruz@gmail.com
}

Revista Moara, n. 52, jan-jul 2019 ISSN: 0104-0944

Recebido em 12/04/2019

Avaliado em 20/05/2019 
1857, second series, from April of 1861 to October of 1862) and the yearbook Álbum do Grêmio Literário Português (1858), daily documents valued by the Cultural History, we will seek to uncover some topics of interest of these Portuguese writers residing in the capital of Brazil, such as the homesickness of the homeland, the setting in the new land, the readings they made and, above all, the image of the Portuguese immigrant that they spread in their leaves.

KEYWORDS: Nineteenth-century periodical press. Immigration. Portuguese-Brazilian relations. Immigrant newspapers

No ano em que se comemoram, em Belém, os 150 anos do Grêmio Literário Português ${ }^{1}$, logo após o $180^{\circ}$ aniversário do Real Gabinete Português de Leitura ${ }^{2}$, no Rio de Janeiro, é importante nos perguntarmos quem eram esses portugueses que continuavam vindo, em levas cada vez maiores, para a ex-colônia, que associações fundavam, com quais objetivos e o que produziam. Por isso, propomo-nos aqui a apresentar uma instituição homônima à paraense, o Grêmio Literário Português do Rio de Janeiro, fundado em 1855 e que deixou de existir em algum momento ao longo da década seguinte.

Por que apresentar uma entidade que teve vida tão curta se há outras que se perpetuaram? Em primeiro lugar, porque acreditamos que há processos que se repetem na história dessas associações lusas no Brasil. Logo, conhecer o Grêmio Literário Português do Rio, seus sócios e seus projetos, seu crescimento e seu declínio, ajuda a compreender a existência e mesmo a sobrevivência de outras agremiações da colônia. Em segundo lugar, porque a partir do Grêmio é possível traçar uma genealogia do associativismo português no Rio de Janeiro. E também porque esse órgão tinha uma característica específica, o desejo de publicar periódicos, o que nos permite ter acesso às produções literárias de um grupo de imigrantes. Se esses motivos não são suficientes, podemos acrescentar que, em algum momento, ao lado de diversos nomes ignorados hoje em dia, participaram das atividades do Grêmio Literário Português do Rio de Janeiro alguns escritores conhecidos ao menos por quem pesquisa a literatura lusobrasileira oitocentista, como José Feliciano de Castilho, Faustino Xavier de Novais,

\footnotetext{
${ }^{1}$ Fundado em 1868.

${ }^{2}$ Fundado em 1837.

Revista Moara, n. 52, jan-jul 2019 ISSN: 0104-0944

Recebido em 12/04/2019 
Emílio Zaluar e inclusive o jovem Machado de Assis. A história dessa instituição está, portanto, vinculada a um momento importante no campo literário brasileiro.

Para resgatarmos a história de parte desse associativismo luso, nomeadamente aquele voltado às atividades culturais, devemos fazer uma viagem. O destino é o Rio de Janeiro na noite de 12 de fevereiro de 1855 . Vamos ao alto de um dos muitos sobrados do Centro da cidade, onde se reunia um grupo de doze jovens imigrantes portugueses. Depois do expediente no comércio, que muitas vezes se estendia após se fecharem as portas do estabelecimento, para que o jovem caixeiro arrumasse a loja, organizasse o estoque e fechasse o aviamento de um pedido, conforme explica Hélio Damante (1964), eles se juntavam para estudar e discutir entre si o que aprendiam. Era a Sociedade LusoInstrutiva, formada inicialmente por seis mancebos e já em seu limite regimental de uma dúzia de sócios - talvez pela própria limitação de espaço para reuniões. Nesse dia, foram visitados por mais um jovem, Bernardino Pinheiro, natural de Coimbra, que viera ao Rio depois de cursar em Lisboa a Escola de Comércio ${ }^{3}$. Ele trazia uma ideia que marcaria a trajetória desses rapazes, fundar uma folha literária.

O trabalho no comércio varejista nas principais cidades do país era um desejo dos jovens imigrantes desde que saíam de Portugal. Ainda na década de 1840, periódicos como a Revista Universal Lisbonense alertavam para o perigo da "escravatura branca" a que seriam submetidos os portugueses que viessem para cá, sem instrução e com dívidas da travessia, principalmente se fossem destinados à lavoura. Mesmo trabalhando no comércio urbano, os portugueses não tinham vida fácil. Enquanto o Gabinete Português de Leitura funcionava no campo específico do fomento à leitura, permitindo acesso a vários livros e periódicos, em outras sociedades instrutivas e literárias, o rapaz comerciante complementava sua formação entre seus pares, que teriam passado pelas mesmas condições. Aqui, o patrão português preferia empregar o jovem patrício, segundo Gilberto Freyre, "em face da disciplina severa a que tinha de submeter-se nos armazéns e lojas o caixeirinho vindo de Portugal para o nosso País, quase como escravo. Escravo louro cuja formação se fazia dentro do próprio armazém despoticamente patriarcal e monossexual" (FREYRE, 2004, p. 389-390). Assim, associações como o Grêmio realizavam sessões com esses jovens mancebos, que se reuniam à noite no alto dos sobrados do Centro da cidade discursando a favor ou

\footnotetext{
${ }^{3}$ (cf. SILVA, 1867, tomo 8, p. 387).
}

Revista Moara, n. 52, jan-jul 2019 ISSN: 0104-0944

Recebido em 12/04/2019 
contra um determinado tema proposto para aquela reunião, como podemos ver num texto memorialista escrito por Reinaldo Carlos Montoro (A Saudade, n. 12, 15/09/1861, p. 97), no qual se comenta um desses serões:

\begin{abstract}
Era pelo anno de 1857. No Rio de Janeiro, em uma casa esguia e tisnada, em frente á igreja do Rosario, reuniam-se todos os domingos no segundo andar alguns jovens do commercio. Alli, á luz de duas vellas humildes, sentados em bancos de páo tosco, praticavam folgadamente de materias de estudo e opinião. Eram todos quasi desconhecidos no mundo das letras. Vindos de além-mar, a maior parte das serranias e valles do norte de Portugal, não haviam trazido nas arcas de pinho grande cabedal de sciencia. Eram aventureiros da intelligencia vindos em troco com os da fortuna. ().
\end{abstract}

Esses "aventureiros da inteligência" não procuravam novas terras, demandavam sim uma nova posição social, algo que os fizesse crescer a nível pessoal e, sobretudo, como grupo. Eles queriam romper com o estigma de brutos provincianos sem instrução espalhado pela lusofobia brasileira da época. O estudo era necessário para essa mudança. A divulgação de suas obras, uma condição para o reconhecimento, tanto aqui quanto em Portugal.

Todavia, a proposta de criação de uma folha literária não agradou à pequena Sociedade Luso-Instrutiva. Dos doze membros iniciais, apenas metade se alinhou à proposta de uma associação literária que publicasse um periódico. Foi o primeiro rompimento de vários que marcariam a genealogia dessa entidade. O grupo que permaneceu tratou de procurar novos companheiros para o recém-criado Grêmio Literário Português e de projetar seu primeiro periódico, A Saudade.

O convite à colaboração foi publicado no Diário do Rio de Janeiro, em julho de 1855 e em outros jornais da Corte: "Convidamos para uma missão santa, para derramar a instrucção entre o povo, para engrandecer a lingua de Camões e de Bocage, dos cantores de Lindoya e de Caramurú". (DIARIO DO RIO DE JANEIRO, 1855, p. 2).

O projeto realmente arregimentou novos membros para a associação, que ganhou prestígio. Manter e fazer crescer uma entidade dessas não é fácil hoje, e era algo quase heroico naquela época. É o que podemos ver no artigo do Correio da Manhã, do Rio de Janeiro, de novembro de 1911, quando do fechamento do Retiro Literário Português: 
Uma dissenção intestina do Gremio deu origem ao Retiro Literario Portuguez. Sem abandonar o Gremio, antes continuando a dispensar-lhe seus carinhos, Constantino de Lemos juntou em torno do seu emprehendimento os homens de quem pôde cercar-se e em 30 de junho de 1859 nascia, numa loja na rua do Rosario, modestamente, timidamente, a nova instituição que deveria resistir a mil inclemencias e atravessar com altivez e honra mais de meio seculo de glorias... e de dissabores.

Ora, fazerem, portuguezes naquella época uma associação literaria não era coisa de pouca monta. Só quem conheceu aquelles tempos, quem nelles viveu, póde dizer hoje o que era o carrancismo dos patrões, e o gráo de servidão a que ficavam subordinados os empregados do commercio. (Correio da Manhã, n. 3458, 05/11/1911, p. 3).

As dificuldades enfrentadas pelo Retiro Literário Português não eram muito diferentes daquelas com as quais as diretorias do Grêmio precisavam lidar, como questões financeiras causadas por sócios que não cumpriam com suas obrigações, também falta de espaço próprio, associados com pouco tempo disponível para colaborar com a entidade, além de brigas internas por motivos diversos. Como vimos, o Retiro surgiu de uma discussão entre seus membros. Mais tarde, o próprio Retiro Literário sofreria com nova divergência, levando à criação do Liceu Literário Português, que resiste até hoje. Os principais motivos para o descontentamento de parte dos sócios era a disputa sobre o foco de ação de cada instituição. O fato de ser associação cultural, sem meios próprios de obter dividendos, era uma das causas de encerramento de entidades criadas pelos imigrantes lusos, como podemos ver nas palavras de Luís Guimarães Júnior que, em 1892, aplaude os esforços da nova diretoria para a manutenção das atividades do Retiro:

É o Retiro Litterario Portuguez uma associação cujos fins hão sido sempre os da cultura do espirito.

E eis porque é uma associação pobre, porque as cousas do espirito no Brazil não têm cotação nos mercados.

No Rio de Janeiro as associações em geral, que não miram a interesses praticos, são como essas plantas inacclimaveis nos tropicos e que nunca chegam a ter viço nem florescencia. [...]

As associações litterarias, mais que quaesquer outras, estão sujeitas a crises. (O Tempo n. ${ }^{\circ} 229,10 / 01 / 1892$, p. 3, grifo do original)

Foi este o destino do Grêmio Literário Português do Rio de Janeiro, associação de vida curta. E mesmo o do Retiro, que encerrou suas atividades no início do século XX. Por outro lado, foi graças aos esforços pela manutenção das entidades e às suas tentativas de publicação de periódicos que podemos hoje ler o que produziam esses portugueses imigrantes. Apesar de serem edições de uma associação que se dissolveu, 
com produções de uma série de autores não canônicos - tanto no Brasil, onde escreveram e publicaram, quanto em Portugal, de onde partiram -, ao ampliarmos nosso horizonte de investigação para esse grupo, estaremos reconstituindo parte da história da colônia portuguesa no Rio de Janeiro, sobretudo pelo seu viés de atuação cultural e formativa, e também esperamos conhecer melhor um ramo da imprensa periódica brasileira e da literatura produzida aqui em meados do Oitocentos. Afinal, se estudos recentes sobre o periodismo brasileiro no segundo reinado ${ }^{4}$ começam a destacar a circulação literária fora da Corte por meio da análise de jornais e revistas das províncias, reequacionando o papel de diferentes autores e meios de divulgação na formação de nossa literatura, a investigação sobre as origens da imprensa dos imigrantes portugueses na capital do império e sua relação com periódicos de maior circulação e durabilidade ainda demanda novos olhares.

Assim, ao analisarmos as publicações do Grêmio Literário Português, sem tomálas como coletâneas de textos, mas como elementos que unem uma multiplicidade de discursos, podemos revelar seus autores, pois,

\begin{abstract}
expulsos da história literária, esses anônimos entram em cena a partir do momento em que o periódico é tomado como suporte e fonte primária, por onde circularam várias vozes e vários discursos, em um pulsar heterogêneo e variado, que pode revelar múltiplas perspectivas de uma época e maneiras desiguais de se apropriar e de se aproximar da cultura escrita (BARBOSA, 2007, p. 40).
\end{abstract}

Podemos perceber dessa forma que, em geral, todas essas associações partilhavam a mesma motivação. Por um lado, incentivando os jovens a preparem discursos e a defenderem ideias sobre diversos temas; por outro, divulgando suas produções por meio de um periódico literário. Cabe a ressalva de que era considerada literária uma variedade de gêneros mais ampla do que hoje em dia. Estudos históricos, leitura dos clássicos, relatos de viagem, poemas, narrativas ficcionais e memórias faziam parte do que poderia ser publicado n'A Saudade. Por outro lado, as ideias sobre a melhor forma para o desenvolvimento dos jovens divergiam. Os custos de publicação de um periódico assim eram altos e o número de assinantes pagantes, baixo. A verba do Grêmio estava sendo toda revertida para sua publicação, que acabou por ser interrompida. Na disputa, parte de seus associados fundou o Retiro Literário Português.

\footnotetext{
4 (MARTINS, 2013); (BRAGANÇA \& ABREU, 2010); (BARBOSA, 2014), entre outros.

Revista Moara, n. 52, jan-jul 2019 ISSN: 0104-0944

Recebido em 12/04/2019 
Mais tarde, um grupo que considerava a oferta de cursos de formação mais importante do que saraus literários e outros eventos resolveu fundar o Liceu Literário Português. As três instituições, ou as quatro, se recordarmos a Sociedade Luso-Instrutiva, partilhavam os mesmos ideais de formação dos jovens da colônia, mas propunham formas de ação diversas.

As diferenças entre o Grêmio e o Retiro não eram assim tão grandes. Apesar de a primeira série d'A Saudade ter sido a causa do afastamento de alguns sócios, as duas entidades criaram periódicos literários ${ }^{5}$. O Grêmio Literário foi o responsável pelo periódico cujo título marca a identidade portuguesa, A Saudade. Essa revista foi publicada entre 5 de agosto de 1855 e 8 de fevereiro de 1857, quando foi encerrada por motivos financeiros. A publicação retornou, em segunda série, entre 15 de abril 1861 e 5 de outubro de 1862. Entre as duas séries, o Grêmio publicou o anuário Album do Gremio Litterario Portuguez no Rio de Janeiro, em 1858, sem continuidade.

Tanto o Grêmio quanto o Retiro, além dos periódicos, organizavam reuniões semanais e alguns saraus. 1862 foi um ano importante para essas duas associações portuguesas, que então abriam suas portas para a sociedade carioca. No dia 5 de julho daquele ano, o Grêmio realizou um sarau literário e artístico nos salões da Phil'Euterpe, com cerca de duzentas pessoas ${ }^{6}$. No dia 19 do mesmo mês, reunindo quinhentas pessoas $^{7}$ no mesmo local, o Retiro Literário Português seguiu o exemplo. Na ocasião, o presidente honorário do Grêmio, Reinaldo Carlos Montoro, discursou elogiando a atitude:

\begin{abstract}
O Gremio Litterario Portuguez no Rio de Janeiro não podia presenciar com indifferença esta emulação nobre, que vinha após tão poucos dias repetir aquella noite de poesia [...] Iniciador de uma ideia feliz nesta terra hospitaleira, vê com satisfação que o ponto luminoso não desappareceu do horizonte em que o traçára, e que hoje mãos mais firmes, mais provadas nas lides do estudo, o vão tornar ainda mais brilhante, mais duradouro, por essas noites de encanto, em que se hão de repetir estes primeiros ensaios. ( $A$ Saudade, n. 7, 27/7/1862, p. 65).
\end{abstract}

\footnotetext{
${ }^{5}$ O Retiro publicou: entre 1 de janeiro e 15 de dezembro de 1860 A Messe - periodico da Sociedade Retiro Litterario Portuguez; em 1870, o Archivo do Retiro Litterario Portuguez no Rio de Janeiro; e entre 30 de julho de 1882 e 31 de dezembro de 1885, a Revista do Retiro Litterario Portuguez.

${ }^{6}$ Segundo relato no Diario do Rio de Janeiro, n. 185 , de 7/7/1862, p. 1

${ }^{7}$ Segundo relato no Diario do Rio de Janeiro, n. 199, de 21/7/1862, p. 1
} 
No mesmo número d'A Saudade, o cronista também comenta o sarau do Retiro. Nesse texto, há elogios sobretudo a três literatos que se destacaram nesse evento: Emílio Zaluar, Machado de Assis e Faustino Xavier de Novais:

\begin{abstract}
A reputação litteraria dos Srs. Zaluar e Machado de Assis, já ao abrigo de toda a contestação, recebeu nesta noite uma consagração estrepitosa. A poesia - Os Rios - do primeiro tem o cunho grandioso da natureza brazileira, e a sublimidade de ideias que inspira este céo de contornos dourados aos que sobem pelas encostas de suas magnificas serras. O segundo, em uma poesia singela, delicada, e maviosamente metrificada, commoveu todo o auditorio. [...]

O Sr. Novaes, em uma bella prosa satyrica, tornou o publico mais ancioso pela proxima publicação do Futuro, em que a sua penna ha de expôr ao publico a riqueza inesgotavel de espirito que possue (A Saudade, n. 7, 27/7/1862, p. 72).
\end{abstract}

O Futuro, revista literária do Faustino, que contava com intensa colaboração de Machado de Assis e de Camilo Castelo Branco, acabaria por impossibilitar a continuação d'A Saudade, por terem basicamente o mesmo público.

Quanto à alegada "cor local” brasileira, motivo de elogios ao poema de Emílio Zaluar, ela não é comum nas produções publicadas nos periódicos do Grêmio. Então, além desses nomes mais destacados, o que produziam os outros portugueses associados ao Grêmio Literário, responsáveis pelas duas séries da Saudade e pelo Album do Grêmio? O prefácio deste último, dedicando a publicação a Alexandre Herculano, é elucidativo da relação desses jovens com a Literatura: "É talvez ousada empreza que de homens do povo, alheios ás praticas litterarias, saia o commettimento de escrever sobre tão variados assumptos [...]” (ALBUM, p. VI-IX).

Como homens do comércio, muitos deles autodidatas, aprendendo seu caminho pelas belas letras praticamente sem mestres, apoiando-se e espelhando-se uns nos outros, não admira que seus temas e estilos não variassem muito (as saudades da infância em Portugal, da família ou da namorada que deixaram são constantes), como se lê, por exemplo, no texto de Fernando Castiço, no Album:

Ah! Julia, tu não sabes o que é viver sem patria...

[...] Todos os dias a esta hora, neste logar triste e solitario, sentado n'uma pedra que as folhas largas e verde-negras d'uma mouta de bananeiras occultam, eu sonho com minha querida patria... fallo com minha boa mãe que me abençoa... e vejo-te triste encostada ás janellas do teu quarto.

Se ao menos podesse sonhar sempre assim... (Album, p. 26). 
Ou, de forma mais poética, Bernardino Pinheiro, em "O emigrado", que começa por contrastar a vida triste no Brasil com sua infância em Portugal:

\footnotetext{
Minha irman, como é triste esta vida,

Tam distante da terra natal;

Não te lembras dos dias passados,

La nas varzeas do bom Portugal.
}

Refere-se o sujeito a quando conheceu o primeiro alvo de seu amor: "Minha irman, não te lembras d'amiga,|Companheira de nós, infantil,|De Lucinda de louros cabellos, $\mid$ Com seus olhos celestes d'anil?”. Concluindo com o desejo de voltar à terra Natal, reencontrar a família e se casar com seu primeiro amor:

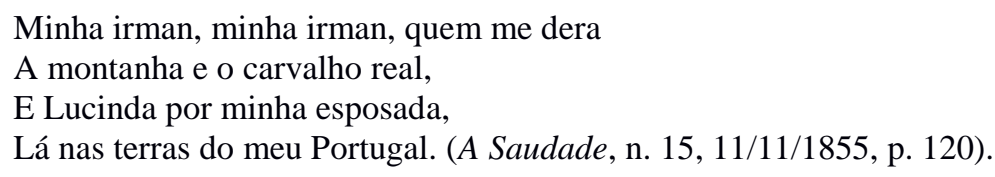

Ou ainda, o poema "Hoje...", de Ernesto Cibrão: “Terra dos Lusos, minha terra querida!/ - Talvez perdida para o trovador - / Patria, que adoro, se te adoro tanto, / Deixa que o pranto dulcifique a dor!" (Album, p. 189).

Curiosamente, esse tema apresenta pouca variedade, ignorando a dificuldade que os fez emigrar e seu cotidiano brasileiro. Inclusive, o ambiente local é pouco abordado por esses escritores, com raras exceções. É o caso, por exemplo, de algumas narrativas curtas, como "O Suicida”, de J. J. d'Oliveira, da primeira série d'A Saudade, que começa no Paço Imperial (A Saudade, n. 3, 19/08/1855), atravessa a baía de Guanabara em noite de tempestade e termina com um duplo assassinato e um suicídio nas praias niteroienses (A Saudade, N. ${ }^{\circ}$ 4, 26/08/1855); ou ainda, “As órfãs de Icaraí" e "A exilada de Ipiabanha", ambas de Reinaldo Carlos Montoro, publicadas na primeira e na segunda séries dessa revista.

$\mathrm{Na}$ poesia, pouco se percebe o cotidiano brasileiro na vida desses poetas. A vida comercial do caixeiro estava ligada à dos negros escravizados, que circulavam pelas ruas do Centro da cidade, vendendo produtos ou fazendo serviços para seus senhores. No entanto, essa relação deve ter motivado "O Canto da Escrava", de J. F. Teixeira e Souza: 
Ai de mim que sou pobre africana,

Triste escrava, meu Deos, sem ventura!

Ai de mim que são negros os dias

No desterro que a vida amargura!

Oh! adeus, doces terras do Congo,

Onde fui entre tantas ditosas;

Nesta terra em que vivo captiva

Por vós sempre suspiro saudosa.

Ai, foi lá, minha terra, que a infancia

Eu só via correr docemente!

Pelas terras suspiro da patria

Onde tudo gosei livremente.

Quantas vezes medito e me lembro

Da cabana em que a luz conheci...

De meus pais, dos parentes e amigos,

Sabe Deos e só Deos... se os perdi! (A Saudade, v. III, n. 20, 11/01/1857, p. 159).

O sujeito lírico pode ser uma africana escravizada e trazida para o Brasil, mas a relação estabelecida com a infância e com a terra natal é a mesma que esses portugueses demonstram quando pretendem falar de si. Há, nesse poema, apenas uma transposição do imigrante para o escravizado, de Portugal para a África, como se as condições da partida, da viagem e da vida no império brasileiro fossem as mesmas para os dois grupos, quando sabemos que não eram bem assim.

Destacamos, contudo, um poeta que, em algumas de suas produções, apropriase da vida do jovem português no Rio de Janeiro e a representa. É o caso de José Coelho Lousada, irmão do romancista portuense Antônio Coelho Lousada que escreveu $O s$ Tripeiros e era sócio-honorário do Grêmio. José tinha, na década de 1860, um escritório de comissões $^{8}$ e fez parte, em 1865, da mesa provisória da Arcádia Fluminense, justamente com José Feliciano de Castilho Barreto e Noronha, Reinaldo Carlos Montoro, e outros ${ }^{9}$. Na mesma Arcádia em que Machado representou a peça Os deuses de casaca.

No poema que Coelho Lousada intitulou "Na minha estreia", por ter que recitar num sarau, o sujeito comenta sobre os versos que não deveria fazer, representando um pouco da vivência comezinha dos trabalhadores do comércio:

Mas porque não farei os meus versinhos

\footnotetext{
${ }^{8}$ Diario do Rio de Janeiro, n. 238, 1869, p. 4.

${ }^{9}$ Jornal do Commercio, n. 283, 1865, p. 2.
}

Revista Moara, n. 52, jan-jul 2019 ISSN: 0104-0944 Recebido em 12/04/2019 


\author{
D'extasiar \\ A uns olhos... de couve, aos labiosínhos \\ D'um alguidar? \\ Nem solto um canto livre, arrebatado \\ Ao meu paiz, \\ D'onde vim saudoso e desterrado, \\ Porque bem quiz; \\ E a meus feitos de rapaz (fiel memória \\ Quão grata me és!) \\ Coroados de junco e palmatória, \\ De pontapés? (ÁLBUM, p. 49-50)
}

Assim, aproximando a vida simples desses portugueses do comércio com a poesia, satirizando aqueles que se comovem com os feitos de rapaz em saudades de Portugal, Coelho Lousada cria algo original nesses periódicos do Grêmio Literário. Se a maioria dos sócios e colaboradores eram caixeiros arvorando-se em escritores, o jogo humorístico que José Coelho Lousada estabelece entre os modelos de composição poética e o dia a dia da casa comercial funciona como uma caricatura do grupo no poema "O caixeiro literato":

\title{
O CAIXEIRO LITERATO
}

D'olhar espantado, sonhando c'o a gloria O sabio caixeiro, é assim que o vês; Entrou um patinho, não conta uma historia Não soube agradar-lhe, perdeu o freguez.

Se pensa absorto nas cousas de Roma Nas cousas dos gregos, das gregas tambem, Ai! logo se engana fazendo uma somma, E o amo, coitado, lá perde um vintem.

Se o covado estende ao longo da téla De luxo, que ás damas arranca bons ais; Sonhando em amores, aos tombos com Ella Lá deu, despachando, trez quartas de mais.

E então... se elle canta em estylo balofo Seu Deus, sua patria, seus hymnos d'amor! Emquanto as fazendas se estragam com mofo Baratas, e ratos, a traça, o bolor!...

De noite, das trovas entregue ao deleite, Que nodoas no panno, nos livros, no chão, Que montes de sebo, que rios d'azeite, Que cheiro embirrante de negro morrão!

Se o vate, cansado, cahio sem alentos 
Nos versos cadentes, na prosa a scismar!...

Só não se recorda da falta de assentos,

E o amo, coitado, que os possa aturar!...

Rio de Janeiro, Agosto de 1857.

J. Coelho Lousada (Álbum, p. 76-77).

Ao relacionar o "estilo" dos versos dos colegas com "mofo" e "bolor", as "trovas" compostas com sujeira e mau odor, a reflexão sobre os clássicos com o engano nas contas, e a musa com o luxo, Lousada deprecia aquelas produções cheias de lugares comuns e as próprias tentativas literárias dos trabalhadores no comércio.

O escritor portuense em terras cariocas não destoa de seus colegas do Grêmio Literário apenas pela sátira à sua própria condição. O convívio com os negros do Rio de Janeiro também serviu de mote a um de seus poemas. Diferentemente do "Canto da Escrava" que era praticamente um poema de saudades de Portugal com outros topônimos, Coelho Lousada apresenta o colorido e a linguagem de outras figuras urbanas do Rio de Janeiro bem próximas dos portugueses, como negras, mestiças ou mulatas, com as quais muitos se amigaram e até casaram, como indica Gilberto Freyre $^{10}$. O poeta resgata do cotidiano carioca um desses tipos, com recolha de vocabulário que ele devia ouvir pelas ruas da cidade, inclusive alguns de origem africana, para compor "A Quitandeira", com toda a graça das situações e da cor local representadas:

\section{A QUITANDEIRA}

Passeio nas ruas vendendo quitanda,

Com saias vistosas de alegre matiz;

A dama nos bailes mais leda não anda,

Não tem mais encantos na scena uma actriz.

Aos chôchos requebros d'alguns velhos songas,

Que fallam de amores co'a bolça na mão,

Resposta tão prompta lhes dou ás candongas,

Que os deixo pasmados de minha isenção.

Creoula briosa, não quero uma chufa,

Embora estas faces não possam corar;

Quitanda vendida, - é paga e não bufa

Que comprem, se querem, ou ponham-se a andar.

Lambida grisette com tantas tetêas,

${ }^{10}$ cf. FREYRE, (2004, p. 387-388).

Revista Moara, n. 52, jan-jul 2019 ISSN: 0104-0944

Recebido em 12/04/2019

Avaliado em 20/05/2019 
Com peitos postiços, com saias-balões,

Nos homens não lança mais fortes cadeias,

Não pode causar-lhes mais loucas paixões.

O Chico soldado, que toca marimba,

Que geme saudades e em graças s'esvae,

Gastou-se-lh'a prosa, que ensina a tarimba,

Não pôde arrancar-me dos braços d'um pae.

Não temo ciladas, não temo quebrantos,

Affoita confio nos meus patuás;

E a tia Cath'rina por artes de encantos

É que hade casar-me co'um bello rapaz.

Sou preta, é verdade, que vendo quitanda;

Que tenho com isso, se vivo feliz?

A dama nos bailes mais leda não anda,

Não tem mais encantos na scena uma actriz.

(Album, 1858, p. 183-184, grifos do original).

Vimos aqui um breve panorama do que foi e do que produziu uma das associações dos imigrantes portugueses no Brasil, congênere de muitas outras, antepassada direta do ainda existente Liceu Literário Português. Quantas instituições como essa existiram por todo o Brasil? O que queriam esses portugueses? O que produziram? É uma longa história do associativismo português no Brasil ainda por fazer. Apesar da vida curta, o Grêmio Literário Português no Rio de Janeiro conseguiu congregar nomes importantes do período, que conviveram e dividiram espaço com escritores menores e mesmo com jovens imigrantes que apenas queriam mais estudo e alguns momentos de lazer. Mesmo com toda a dificuldade, esses jovens literatos publicaram três vezes periódicos para dar publicidade a suas próprias produções literárias, que ficaram para a posteridade e nos permitiram hoje conhecer um pouco do que faziam e como viviam.

Em um período como o nosso, em que balsas naufragam no Mediterrâneo e corpos são arrojados às praias, em que bolivianos e chineses são encontrados como escravos em confecções e pastelarias no Rio e em São Paulo, em um tempo em que a diáspora volta a ser um tema mundialmente importante, é preciso reconhecer a dificuldade da vida fora da pátria e evitar que a história de sofrimento e preconceito se repita. Mais um motivo para valorizarmos essas "obras tão dignas de memórias", recuperando o verso camoniano utilizado como motivação aos sócios do Grêmio por seu presidente, o poeta Francisco Gonçalves Braga. Essas obras, em muitos casos, podiam ser apenas a sobrevivência num país estrangeiro, mas também eram produções 
literárias e periódicos, como esses apresentados aqui, além da série de associações que ajudaram das mais variadas formas esses portugueses no Brasil, como em Belém o Grêmio Literário Português.

\section{REFERÊNCIAS}

BARBOSA, Socorro de Fátima P. (Org.). Livros e periódicos nos séculos XVIII e XIX. João Pessoa: Editora da UFPB, 2014.

BRAGANÇA, Aníbal; ABREU, Márcia (orgs.). Impresso no Brasil: dois séculos de livros brasileiros. São Paulo: Editora da UNESP, 2010.

DAMANTE, Helio. O Caixeiro Português. Suplemento Literário d'O Estado de São Paulo, São Paulo, n. 380, p. 2, 16/05/1964.

Diário do Rio de Janeiro, n. 238, 1869, p. 4.

Diário do Rio de Janeiro, n. 192, 13/07/1855, p. 2

FONSECA, Vitor Manoel Marques da. Associativismo português no Rio de Janeiro, 1903-1909. In: MARTINS, Ismênia de Lima; SOUSA, Fernando. (Org.). Portugueses no Brasil: migrantes em dois atos. 1. ed. Niterói: Muiraquitã, 2006, v.?, p. 136-161.

FREYRE, Gilberto. Sobrados e Mucambos: decadência do patriarcado e desenvolvimento do urbano. 15. ed. São Paulo: Global, 2004.

JORNAL do Commercio, n. 283, 1865, p. 2.

MARTINS, Ana Luiza. Imprensa em tempos de Império. In: MARTINS, Ana Luiza; DE LUCA, Tania Regina (Orgs.). História da imprensa no Brasil. 2. ed. 2. reip.. São Paulo: Contexto, 2013.

A Saudade, n. 3, 19/08/1855

A Saudade, n. 15, 11/11/1855, p. 120

A Saudade, v. 3, n. 20, 11/01/1857, p. 159.

A Saudade, n. 7, 27/7/1862, p. 72.

SILVA, Innocencio Francisco da. Diccionario Bibliographico Portuguez: estudos applicaveis a Portugal e ao Brasil. Lisboa: Imprensa Nacional, 1858-1958. v. 23.

O Tempo n. 229, 10/01/1892, p. 3. 
